\title{
CORRECTION
}

View Article Online

View Journal | View Issue

Check for updates

Cite this: J. Mater. Chem. A, 2021, 9 , 1868

DOI: $10.1039 / d 1 \operatorname{ta9} 0006 d$

rsc.li/materials-a

\section{Correction: Rational construction of hierarchical SAPO-34 with enhanced MTO performance without an additional meso/macropore template}

Yafei Liang, ${ }^{a}$ Beibei Gao, ${ }^{* a}$ Lipeng Zhou, ${ }^{a}$ Xiaomei Yang, ${ }^{a}$ Tianliang Lu, ${ }^{\text {b }}$ Hongchang $\mathrm{YaO}^{\mathrm{a}}$ and Yunlai Su*a

Correction for 'Rational construction of hierarchical SAPO-34 with enhanced MTO performance without an additional meso/macropore template' by Yafei Liang et al., J. Mater. Chem. A, 2021, DOI: 10.1039/ d0ta08437a.

The authors regret that an incorrect value was quoted in the published article for the selectivity of ethylene and propene for sample SAPO-34-C, due to a calculation error.

Specifically, in Table 3, the average selectivity of ethylene and propene for sample SAPO-34-C should be 81.03, rather than 75.60. Additionally, in the section 'Catalytic performance in the MTO reaction', the sentence the average selectivity of ethylene and propylene of sample SAPO-34-H2 is higher than that of the conventional catalyst, which is improved from $75.6 \%$ for the conventional SAPO-34-C catalyst up to $81.6 \%$ should instead read as follows: the average selectivity of ethylene and propylene of sample SAPO-34-H1 is higher than that of the conventional catalyst, which is improved from $81.03 \%$ for the conventional SAPO-34C catalyst up to $81.84 \%$. This error does not affect the overall conclusions of the article.

The Royal Society of Chemistry apologises for these errors and any consequent inconvenience to authors and readers. 